\title{
Impactos da Reestruturação do Setor de Celulose e Papel no Brasil sobre o Desempenho de suas Indústrias
}

\author{
Adriana Estela Sanjuan Montebello \\ Professora - Depto. de Tecnologia Agroindustrial e Sócioeconomia Rural (DETAiSER-UFSCar) \\ Endereço para contato: Rodovia Anhanguera, Km 174 - Araras - SP \\ Caixa Postal 153 - CEP: 13600-970 - E-mail: adrianaesm@cca.ufscar.br \\ Carlos José Caetano Bacha \\ Professor - Departamento de Economia, Administração e Sociologia (ESALQ/USP) \\ Endereço para contato: Avenida Pádua Dias. 11 - Piracicaba - SP \\ CEP: 13418-900 - E-mail: carlosbacha@usp.br
}

Recebido em 18 de julho de 2011 . Aceito em 29 de novembro de 2012.

\section{Resumo}

Este artigo tem como objetivo determinar, por meio da estimativa de equações com dados organizados em painel, se as variáveis que medem a estrutura e a abertura comercial tiveram influência sobre o desempenho das indústrias de celulose e das indústrias de papéis e de artefatos de papéis no Brasil (essas duas últimas tomadas em conjunto). O período de tempo considerado na análise foi o de 1986 a 2007 e os dados utilizados são oriundos da Pesquisa Industrial Anual do IBGE e da Associação Brasileira de Celulose e Papel - BRACELPA. Concluiu-se que a variável de concentração de mercado $(\mathrm{HHI})$ - que mede a estrutura - teve impacto positivo sobre a margem preço-custo, que é a medida de desempenho das indústrias citadas. Além disso, o aumento na taxa de importação (que mede a abertura comercial) tem relação negativa com a margem preço-custo e a origem do capital tem relação positiva com a medida de desempenho considerada. Ou seja, o aumento da importância do capital estrangeiro na indústria aumenta o seu desempenho.

\section{Palavras-Chave}

setor de celulose e papel no Brasil, reestruturação, desempenho industrial, dados em painel

\begin{abstract}
This article aims to determine, through the estimative of the equations run with data organized in panel, if the structure and trade openness variables had influence on the performance of pulp, papers and paper-made products industries in Brazil (the last two taken joined). The time period considered in the analysis was from 1986 though 2007 and data used was collected from the Annual Industrial Research prepared by the IBGE and from the Brazilian Pulp and Paper Association - BRACELPA. It can be concluded that the market concentration variable $(\mathrm{HHI})$ - taken as structure indicator - had positive impact on the price-cost margin performance measure. The results also pointed out that the increase in the importation rate (a measure of the economy openness) has
\end{abstract}


negative relation with the price-cost margin and the capital's origin has positive relation with the performance measure considered. The latter suggests the bigger multinational capital inside the industry, lagger its performance.

\section{Keywords}

pulp and paper sector in Brazil, restructuring, industrial performance, panel data

JEL Classification

L16, L52, L69

\section{Introdução}

Denomina-se de setor de celulose e papel o conjunto formado pela indústria de celulose, pela indústria de papéis e pela indústria de artefatos de papéis. ${ }^{1}$ Segundo os dados da Pesquisa Industrial Anual (PIA) do IBGE, o valor bruto da produção do setor de celulose e papel, em 1996, foi de 33,1 bilhões de reais (a preços de 2007) e em 2007 este valor foi de 43,5 bilhões de reais, com as participações, em 1996, de 14,55\%, 29,59\% e 55,87\% para as indústrias de celulose, de papéis e de artefatos de papéis, respectivamente, no valor bruto da produção. Em 2007, essas participações foram de 19\%, 29,38\% e $51,63 \%$, respectivamente. Esses dados mostram que as três indústrias que compõem o setor de celulose e papel tiveram evoluções distintas no período de 1996 a 2007.

A indústria de celulose compõe-se das empresas que produzem celulose (as pastas químicas e semiquímicas de madeira) e pasta de alto rendimento. A celulose pode ser vendida no mercado doméstico e externo (e é chamada de celulose de mercado) ou usada na produção de papel pela própria empresa que a produz (neste caso, a polpa é chamada de celulose de integração). A produção total de pastas de madeira no Brasil foi de 12,7 milhões de toneladas em 2008, segundo dados da BRACELPA. ${ }^{2}$ O grande destaque do Brasil, entre a produção de pastas de madeira, é na produção de celulose de fibra curta de eucalipto, em que o país é o maior produtor mundial. Nessa categoria predomina a celulose branqueada (com produção de

1 O conjunto das três indústrias supracitadas e mais as florestas, que elas detêm, a indústria de editoração e gráfica e os segmentos distribuidores vinculados àquelas indústrias constituem a cadeia produtiva da celulose e papel.

2 Associação Brasileira Técnica de Celulose e Papel - BRACELPA. 
10,61 milhões de toneladas em 2008) utilizada, principalmente, para a fabricação de papéis de imprimir e escrever, papéis sanitários de alta qualidade e papéis de alto valor agregado. A participação dessa categoria no total da produção de pastas de madeira no Brasil foi de $83,6 \%$ em 2008. Já a celulose de fibra longa (geralmente oriunda de madeira de pinus) participou com $12,4 \%$ da produção $(1,58$ milhão de toneladas), predominando nesse caso o tipo não branqueado $(1,47$ milhão de toneladas em 2008), cujo principal uso é na produção de papéis de embalagem. A produção de pastas de alto rendimento (PAR) foi de 507.602 toneladas em 2008, o que correspondeu a $4 \%$ da produção total de pastas de madeira no país.

Em 2008, quatro grupos respondiam por $64,8 \%$ da produção total de polpas de madeira no Brasil, os quais foram Aracruz, Suzano, Votorantim $^{3}$ e Klabin. O principal destino da produção de polpas, em 2008, foi o mercado externo. De acordo com a BRACELPA, $34 \%$ da produção de polpas foi para consumo próprio das empresas, $9,8 \%$ foram direcionadas às vendas internas e $56,2 \%$ da produção foram direcionadas às vendas externas. Os principais mercados de destino dessas exportações foram: Europa $(51,6 \%$ das vendas externas), América do Norte (20,2\%), China (17,6\%), Ásia/Oceania $(9,4 \%)$, América Latina (1\%) e África $(0,1 \%)$. No caso da celulose de fibra curta, $65 \%$ de sua produção nacional tem como destino o mercado externo. Já no caso da celulose de fibra longa e da pasta de alto rendimento, toda a produção fica no mercado doméstico (para consumo próprio das empresas ou para vendas domésticas). No caso da indústria de papéis, a concentração é menor do que na indústria de celulose e a produção de papéis é voltada mais para o mercado doméstico.

A indústria de papéis engloba as empresas produtoras de papéis de imprensa, papéis de imprimir e escrever, papéis para embalagem, papéis sanitários (também chamados de tissue), papel cartão e papéis para outros fins, segundo a classificação da BRACELPA. Esses papéis são vendidos no mercado externo ou no mercado interno, sendo que parte destes últimos se destina às indústrias de embalagens de papel, às indústrias de artefatos de papéis ou às indústrias de editoração e gráfica. Vale destacar que as empresas líderes são verticalizadas (desde a etapa de reflorestamento até a de fabricação de papel) e

3 A Aracruz e a Votorantim fundiram-se, em 2009, criando a Fibria. Como o período em análise nesse artigo é o de 1986 a 2007, aquelas duas empresas são consideradas separadamente ao serem mencionadas. 
as de pequena escala de operação compram a celulose no mercado. As empresas integradas contam com as vantagens competitivas na produção de celulose, a qual é elaborada a partir da madeira de eucalipto e pinus, permitindo o corte mais rápido dessas árvores do que as existentes nos países concorrentes. Destaca-se que, atualmente, a maior parte dos papéis é feita através de fibras de árvores plantadas. No caso do Brasil, o eucalipto é a espécie mais plantada devido ao seu rápido crescimento. As fibras de eucalipto são aptas para gerar celulose a ser utilizada na confecção de papéis de baixa resistência ao rasgo, como os papéis de imprimir e escrever, cartões e sanitários. Em 2008, foram produzidos 9,41 milhões de toneladas de papéis no Brasil. Os quatro maiores produtores de papéis, em 2008, foram Klabin, Suzano, International Paper e Votorantim Celulose e Papel (atualmente agrupado na Fibria). Juntos eles foram responsáveis por $41,2 \%$ do total produzido de papéis nesse ano.

Para consumo próprio foram destinados, em 2008, 25,95\% da produção; para as vendas domésticas, $55,13 \%$; e para as vendas externas, $18,92 \%$ da produção. Essas percentagens mostram que a indústria de papel é mais voltada a atender o mercado doméstico e a indústria de celulose ao mercado externo. Em relação ao consumo de papéis, os países que apresentaram o maior consumo per capita de papéis segundo dados da Resource Information Systems - RISI (2009 apud BRACELPA, 2009) - em 2008, foram Finlândia (341,7 kg/habitante/ ano), Estados Unidos (265,9 kg/habitante/ano), Japão (241,5 kg/habitante/ano), Canadá (208,8 kg/habitante/ano), Reino Unido (184,9 $\mathrm{kg} /$ habitante/ano) e Itália (190,8 kg/habitante/ano). Já o consumo per capita brasileiro de papel é um dos mais baixos do mundo, registrando, em 2008, apenas 44,6 kg/habitante/ano, ainda muito distante dos níveis observados em países mais desenvolvidos ou em estágio de desenvolvimento comparável ao do Brasil (BRACELPA, 2007).

As indústrias que compõem o setor de celulose e papel também possuem estruturas distintas. A indústria de celulose é menos trabalho intensivo do que a de papéis, e esta última é menos trabalho intensivo do que a indústria de artefatos de papéis. Em 2007, segundo os dados da Relação Anual de Informações Sociais (RAIS), 7,01\% do volume de emprego no setor de celulose e papel foi na indústria de celulose, $22,33 \%$ na indústria de papéis e $70,67 \%$ na indústria de artefatos de papel como ressaltado anteriormente; as participações dessas indústrias no VBP foram, respectivamente, 19\%, 29,38\% e 
51,63\% no mesmo ano. A balança comercial da indústria de celulose, em 2007, totalizou US $\$ 2,7$ bilhões de dólares e a da indústria de papéis foi de US\$ 616 milhões (dados da BRACELPA).

O setor de celulose e papel foi, nos anos de 1950 a 1989, bastante favorecido por políticas econômicas que o dinamizaram. No entanto, observa-se que esse setor continuou sua trajetória ascendente nos anos posteriores em que ocorre o processo de globalização, por meio da liberalização do comércio internacional e da consequente interdependência entre os países e com menor intensidade de estímulo de políticas econômicas. Isto tem sido atribuído a fatores de competitividade obtidos no Brasil e que não puderam ser reproduzidos pelos demais concorrentes no mercado global. Entre esses fatores estão o baixo custo de obtenção de madeira e de energia no Brasil e um parque industrial moderno.

Já no início da década de 1990, o quadro das indústrias do setor de celulose e papel foi marcado por inovações incrementais em tecnologia, e houve maior concentração do capital setorial por meio de fusões e aquisições. As exportações brasileiras de celulose aumentaram, entre 1986 a 1990, a 5,08\% a.a (em quantidade); sendo que de 1990 a 2000, houve acréscimo de 9,78\% a.a; e no período de 2000 a 2007, o aumento foi de $12,8 \%$ a.a. As importações de celulose tiveram as seguintes taxas de crescimento entre 1986 a 1990 e de 1990 a 2000: $21,3 \%$ a.a e 19,74\%, respectivamente. Entre 2000 e 2007, houve decréscimo das importações brasileiras de celulose de 5,51\% a.a. As exportações brasileiras de papel (em quantidade) cresceram, entre 1986 e 1990, a 10,94\% a.a; 1,52 \% a.a entre 1990 e 2000; e 7,9\% a.a entre 2000 e 2007. Nesses mesmos intervalos, as importações de papel tiveram os seguintes crescimentos: 2,77\% a.a, 16,95\% a.a e $2,71 \%$ a.a, respectivamente. O Brasil é competitivo no mercado internacional em produtos de baixo valor agregado como a celulose de fibra curta, papéis de imprimir e escrever não revestidos e papéis embalagens da linha kraft.

É importante destacar que o mercado doméstico tornou-se, na verdade, mais contestável devido à rápida adoção da liberalização do comércio e da liberalização para realizar investimento estrangeiro no Brasil, apesar dos aumentos observados na concentração dos setores industriais como forma de responder às mudanças ocorridas no cenário mundial. Segundo Baer (2009), a liberalização do comércio 
implica que o mercado brasileiro está agora mais aberto à competição estrangeira. Nesse sentido, o mercado tornou-se mais contestável, ainda que substancialmente mais concentrado, já que as empresas ficaram mais vulneráveis à entrada e à rivalidade de competidores potenciais, o que pôde inibir possível exercício de poder de mercado das empresas. Baer (2009) destaca ainda que:

"do ponto de vista da política econômica, contudo, o que realmente conta é se as condições aparentemente mais contestáveis dos mercados nos últimos anos foram associadas com melhoras no desempenho competitivo, seja este medido por produtividade, custo unitário ou por inovação." (Baer, 2009, p. 502)

A análise do setor de celulose e papel no Brasil permite uma reflexão sobre a dúvida acima colocada por Baer (2009). As três indústrias que compõem esse setor tiveram configurações distintas ao longo de sua formação e, consequentemente, têm concentrações e contestabilidades distintas, o que deve refletir em distintas evoluções e desempenhos.

Dentro desse contexto, o objetivo geral deste artigo é analisar o impacto da reestruturação e da abertura comercial das indústrias de celulose, papéis e artefatos de papéis no Brasil sobre o desempenho das mesmas. A contribuição deste artigo está em analisar os determinantes do desempenho das indústrias do setor de celulose e papel no Brasil por meio de equações que relacionam o desempenho com alguns dos elementos de estrutura dessas indústrias e com variáveis de abertura comercial, utilizando dados organizados em painel para o período entre 1986 e 2007. Para tanto, consideram-se duas cross section: a indústria de celulose e a indústria de papel e artefatos de papel (estas duas últimas tomadas em conjunto). Dessa forma, buscase analisar as variáveis explicativas dos determinantes do desempenho desse setor antes e após a década de 1990.

O artigo utilizará, além dos fundamentos da teoria de organização industrial, modelos econométricos que buscam quantificar as relações definidas por essa teoria. Apesar de se utilizar o ferramental teórico da Estrutura-Conduta-Desempenho - ECD, que já tem tradição nos estudos de organização industrial para o setor de celulose e papel no 
Brasil, há escassez de trabalhos que fazem análises econométricas para as inter-relações entre estrutura e desempenho. É importante destacar que, no caso brasileiro, ainda são relativamente escassos os estudos de caráter mais quantitativos em Organização Industrial. Além disso, serão utilizados, para analisar os determinantes do desempenho das indústrias que compóem o setor de celulose e papel no Brasil, os elementos teóricos dos mercados contestáveis.

O presente artigo está organizado em mais seis seções, além desta introdução. A seção dois apresenta a revisão de literatura sobre a organização industrial do setor de celulose e papel no Brasil. A seção três apresenta o arcabouço teórico que serve como suporte ao modelo empírico proposto. $\mathrm{Na}$ seção quatro são apresentados os dados e os procedimentos econométricos utilizados. A seção cinco apresenta discutidos os resultados da pesquisa. Por último, a seção seis traz as considerações finais do trabalho.

\section{Revisão de Literatura}

Na literatura há diversos trabalhos analisando a organização industrial do setor de celulose e papel no Brasil. A maioria desses trabalhos destacou a estrutura e o desempenho da indústria de celulose ou da indústria de papéis, ou do setor de celulose e papel como um todo, sem mencionar as diferenças entre seus segmentos. Os trabalhos de Leite (1998), Fonseca (2003) e Lopes (1998) analisaram a estrutura e o desempenho das indústrias brasileiras de celulose e papel de forma conjunta. Já os trabalhos de Hilgemberg e Bacha (2003), Carrazza e Bacha (2004), Silva (2002) e Fonseca (2003), que também estudaram a organização industrial do setor de celulose e papel no Brasil, deram ênfase à estrutura ou ao desempenho da indústria de celulose e da indústria de papéis separadamente.

Trabalhos relacionados à forma como as indústrias de celulose e papel têm procedido à integração vertical também foram encontrados. Os trabalhos existentes na literatura sobre esse tema - Lima et al. (2006), Damani (2004) e Ohanian (1994) - destacam as vantagens e estratégias da integração vertical no setor de celulose e papel. Há, na literatura internacional, trabalhos que realizaram análises econométricas sobre a estrutura e desempenho do setor de celulose

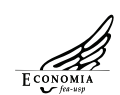


e papel. Tem-se o caso do trabalho de Li, McCarthy e Urmanbetova (2004), os quais estudaram os efeitos das estruturas das indústrias do setor de celulose e papel nos Estados Unidos (por meio do índice de concentração das quatro maiores empresas de cada segmento: indústria de celulose, papel e embalagens de papel) sobre o desempenho das mesmas (utilizando a medida do índice de Lerner como variável de desempenho das indústrias). Também foi testada uma variável de intensidade de importações como forma de verificar se esta teve o papel de inibir o poder de mercado das indústrias desse setor. As principais conclusões apontaram para a existência de uma relação positiva entre a medida de concentração considerada e uma relação negativa entre a variável de intensidade de importações e o desempenho das indústrias do setor de celulose e papel.

Alguns trabalhos, como o de Feijó et al. (2003) e Hay (1997), segundo Carvalho Júnior e Ruiz (2008), analisaram os efeitos do processo de liberalização comercial sobre o desempenho industrial brasileiro, concluindo que o desempenho foi afetado pelo aumento médio da concentração industrial via fusões e aquisições no período posterior à abertura comercial. Assim, vários trabalhos têm estudado a relação entre variáveis de desempenho e concentração industrial como forma de analisar o impacto do processo de reestruturação sobre as indústrias brasileiras. Tal discussão é relevante, segundo Feijó et al. (2003), uma vez que devido ao aumento da competitividade entre os países pressupõe-se que as empresas atuem em grande escala como forma de enfrentar a concorrência e conquistar maior participação de mercado.

De forma geral, os trabalhos encontrados na literatura que utilizaram em suas análises empíricas a relação desempenho e estrutura, geralmente, fizeram um estudo para a indústria brasileira como um todo, não realizando essa análise para um setor industrial específico, ou foram aplicados para os setores industriais de outros países. Devido à escassez de trabalhos sobre essa relação aplicada ao setor de celulose e papel instalado no Brasil, pretende-se avaliar, empiricamente, se as variáveis que medem a estrutura, bem como as variáveis que medem a abertura comercial afetaram o desempenho das indústrias desse setor. Para tanto, pretende-se utilizar dados anuais agrupados em painel e considerar o período entre 1986 e 2007 para as indústrias que compõem o setor de celulose e papel (a indústria de celulose versus a indústria de papel e a de artefatos de papel tomados 
conjuntamente). Vale ressaltar que o período entre 1986 e 2007 foi selecionado devido à disponibilidade de dados para as estimativas a serem feitas, e abrange a fase de consolidação do setor de celulose e papel no Brasil e sua inserção no mercado internacional como forte exportador, especialmente no caso da celulose de fibra curta.

O uso de dados em painel, por sua vez, será útil para o estudo em questão, uma vez que possibilita investigar efeitos econômicos que não podem ser identificados apenas com dados cross section ou apenas com o uso de séries temporais. Além disso, o uso de dados em painel possibilita o emprego de um maior número de observações, melhorando a eficiência das estimativas econométricas.

\section{Referencial Teórico}

\subsection{Os Modelos Empíricos Relacionando Desempenho e Estrutura}

Originalmente, os estudos aplicando a relação entre concentração (variável de estrutura) e desempenho industrial sugeriram que quanto maior é a concentração em um dado mercado, maior é a possibilidade de sinergias entre as empresas, implicando o aumento do poder de mercado e melhoria do seu desempenho. Estes estudos, conforme Tonnoka e Koyama (2003), tiveram grande repercussão no debate acerca do poder de mercado de grandes empresas no mercado norte-americano no final da década de 1960 e no início da década de 1970, influenciando as recomendações de órgãos públicos de defesa da concorrência em favor da desconcentração dos mercados.

Com a abordagem dos estudos iniciados na Escola de Chicago nos anos de 1970, emergiu o debate sobre as questões de eficiência econômica, dando nova explicação para a relação positiva entre grau de concentração e lucratividade. A relação entre estrutura e desempenho sofreu modificações. De acordo com a nova vertente, a concentração industrial é resultado da maior competitividade entre as empresas, resultando em maior eficiência entre estas, as quais passam a produzir com menores custos de produção e, portanto, geram menores custos à sociedade. Nessa linha de raciocínio, alguns estudos - como o de Miller (1969), Gilbert (1984), Smirlock, Gilligan e Marshall (1984), Smirlock (1985) e Molyneux e Forbes (1995), 
seguindo a orientação de Demsetz (1973) e Peltzman (1977) - acrescentaram medidas de participação de mercado juntamente com as de concentração como determinantes do desempenho, como sugere a equação abaixo:

$$
\pi=\beta_{0}+\beta_{1} C R+\beta_{2} M S+\alpha^{\prime} X
$$

em que $\pi$ representa a medida de desempenho da indústria,CR é a medida de concentração do mercado, MS é a participação de mercado e $X$ representa o vetor de variáveis de controle adicionais específico da firma. Há três resultados possíveis na estimação dessa equação: 1) se $\beta_{1}$ é estatisticamente significante e $\beta_{2}$ é estatisticamente igual a zero, prevalece a hipótese estrutura-desempenho - ED - (a qual postula que o desempenho das firmas relaciona-se com o aumento da concentração de mercado e não tem relação com a melhora de eficiência das firmas); 2) se $\beta_{1}$ é estatisticamente igual a zero e $\beta_{2}$ é estatisticamente significante, prevalece a hipótese eficiência-estrutura - EE - (a estrutura, avaliada pela concentração de mercado, é resultado da competição entre as firmas e essas com custos menores aumentam seus lucros, reduzindo preços e expandindo a participação de mercado). O objetivo dessa hipótese é testar a hipótese de Demsetz (1973) de que a lucratividade e a maior concentração da indústria é resultado da maior eficiência das firmas líderes em relação a seus competidores, e não do comportamento colusivo entre elas; e 3) se $\beta_{1}$ e $\beta_{2}$ são estatisticamente significantes, ambas as hipóteses não podem ser rejeitadas.

O Quadro 1 a seguir foi construído com base nos trabalhos citados nos dois parágrafos anteriores, e permite ter uma visão sintética sobre como os autores trabalharam com o ferramental teórico de estrutura e desempenho em suas análises econométricas. Apesar da participação de mercado ter sido utilizada por muitos autores como medida de eficiência para testar a hipótese EE, essa variável tem sido criticada, uma vez que não é possível garantir, a priori, que os efeitos que estão sendo medidos sejam, de fato, oriundos da eficiência, mas sim de outros fatores não associados com a eficiência, tal como o poder de mercado segundo argumentaram Shepherd, 1984; Timme e Yang, 1991; e Berger, 1995 apud Mendonça, Reis e Mendonça (2008). Além disso, alguns autores consideram que o acréscimo da participação de mercado como variável explicativa da 
medida de desempenho pode ocasionar problemas do ponto de vista estatístico devido à provável colinearidade entre essa variável e o grau de concentração. Devido a esses questionamentos, surgiram alguns trabalhos que utilizam medidas diretas de eficiência, ao invés da participação de mercado, para determinar o desempenho. Maudos (1998) e Gumbau e Maudos (2000), por exemplo, calculam medidas diretas de eficiência utilizando o método de estimação de fronteiras estocásticas na estimação de seus modelos, conforme se constata no Quadro 1.

\begin{tabular}{|c|c|c|c|}
\hline & objetivo & modelo & variáveis utilizadas \\
\hline $\begin{array}{l}\text { Miller } \\
\text { (1969) }\end{array}$ & $\begin{array}{l}\text { analisar a relação ED para a in- } \\
\text { dústria manufatureira americana } \\
\text { por meio de dados de painel de } \\
106 \text { indústrias no período de } 1958 \\
1959 \text { a 1961-1962 }\end{array}$ & $\begin{array}{l}\text { equações relacionando o desempe- } \\
\text { nho da indústria com as variáveis } \\
\text { estrutura de mercado e utilizando } \\
\text { o método de minímos quadrados } \\
\text { ordinários }\end{array}$ & $\begin{array}{l}\text { variável dependente: renda líquida; } \\
\text { e variáveis independentes: taxa de } \\
\text { concentração da produção das quatro } \\
\text { e oito maiores empresas, intensidade } \\
\text { de propaganda e grau de diversifica- } \\
\text { ção das empresas. }\end{array}$ \\
\hline $\begin{array}{l}\text { Gilbert } \\
(1984)\end{array}$ & $\begin{array}{l}\text { sintetiza estudos empíricos, } \\
\text { desenvolvidos entre a segunda } \\
\text { metade da década de } 1960 \text { e } \\
\text { início da década de } 1980 \text {, que } \\
\text { analisaram a relação ED nas ins- } \\
\text { tituições bancárias americanas } \\
\text { como forma de fornecer às au- } \\
\text { toridades regulatórias um estudo } \\
\text { quantitativo para avaliar como a } \\
\text { inflência das fusões bancárias } \\
\text { afetam a concorrência e suas } \\
\text { estruturas de custos. }\end{array}$ & $\begin{array}{l}\text { os modelos estimados relaciona- } \\
\text { ram a variável desempenho das } \\
\text { instituições bancárias americanas } \\
\text { (medida de lucratividade) com as } \\
\text { variáveis de estrutura de mercado } \\
\text { (como o grau de concentração). } \\
\text { Também foi estimada a estrura de } \\
\text { custos da indústria bancária. }\end{array}$ & $\begin{array}{l}\text { variável dependente: lucratividade } \\
\text { bancária; e variáveis independentes: } \\
\text { medidas do grau de concentração dos } \\
\text { bancos. }\end{array}$ \\
\hline $\begin{array}{l}\text { Smirlock, } \\
\text { Gilligan } \\
\quad \mathrm{e} \\
\text { Marshall } \\
(1984)\end{array}$ & $\begin{array}{l}\text { testar a hipótese ED e EE para a } \\
\text { indústria manufatureira america- } \\
\text { na no período entre } 1960 \text { e } 1969\end{array}$ & $\pi=\beta_{0}+\beta_{1} C R+\beta_{2} M S+\alpha^{\prime} X$ & $\begin{array}{l}\pi \text { é a medida da razão do q de Tobin } \\
\text { como variável de desempenho, o que } \\
\text { depende da medida de concentração } \\
\text { de mercado (CR) e da medida de } \\
\text { participação de mercado (MS) e de } \\
\text { um vetor } X \text { de variáveis de controles } \\
\text { adicionais específicos da firma. }\end{array}$ \\
\hline $\begin{array}{c}\text { Smirlock } \\
(1985)\end{array}$ & $\begin{array}{l}\text { testar as hipótese ED e EE para o } \\
\text { setor financeiro norte-americano } \\
\text { no período entre } 1973 \text { a } 1978 .\end{array}$ & $\begin{array}{l}\text { foram estimados modelos, seme- } \\
\text { Ihante ao trabalho de Ravenscraft } \\
(1983)^{*} \text {, relacionando a variável } \\
\text { desempenho (lucratividade) com } \\
\text { as variáveis de concetração de } \\
\text { mercado e market share."Nota: } \\
\text { Ravenscraft, D.J. 1983. "Structure- } \\
\text { profit relationships at the Line of } \\
\text { Business and industry level". The } \\
\text { Review of economics and Statistics. } \\
\text { v. } 65, \text { n.1, p.22-31. }\end{array}$ & $\begin{array}{l}\text { variável de desempenho: lucratividade, } \\
\text { e variáveis de estrutura de mercado: } \\
\text { grau de concentração, participação de } \\
\text { mercado e uma variável de interação } \\
\text { entre o grau de concentração e a par- } \\
\text { ticipação de mercado. }\end{array}$ \\
\hline
\end{tabular}


(Continuação)

\begin{tabular}{|c|c|c|c|}
\hline & objetivo & modelo & variáveis utilizadas \\
\hline $\begin{array}{c}\text { Molyneux } \\
\text { e Forbes } \\
\text { (1995) }\end{array}$ & $\begin{array}{l}\text { estimar as hipóteses ED e EE } \\
\text { para a indústria bancária eu- } \\
\text { ropéia no período entre } 1986 \text { e } \\
1989 \text { utilizando dados em painel. }\end{array}$ & $\pi=\beta_{0}+\beta_{1} C R+\beta_{2} M S+\alpha^{\prime} X$ & $\begin{array}{l}\pi \text { é a medida da razão do q de Tobin } \\
\text { como variável de desempenho e que } \\
\text { depende da taxa de concentração de } \\
\text { ativos dos } 10 \text { maiores bancos (CR) e } \\
\text { duas medidas de participação de mer- } \\
\text { cado (taxa de depósito e taxa de ativos } \\
\text { dos bancos) para analisar a hipótese } \\
\text { EE e de um vetor X de variáveis de } \\
\text { controles adicionais específicos da } \\
\text { firma. }\end{array}$ \\
\hline $\begin{array}{l}\text { Maudos } \\
(1998)\end{array}$ & $\begin{array}{l}\text { analisar as hipóteses ED e EE } \\
\text { para a indústria bancária es- } \\
\text { panhola no período entre } 1990 \\
\text { e 1993, acrescentando uma } \\
\text { mdedida de eficiência técnica } \\
\text { ao modelo de Smirlock, Gilligan } \\
\text { e Marshall (1984). }\end{array}$ & $\pi=\beta_{0}+\beta_{1} C R+\beta_{2} M S+\beta_{3} E F+\alpha^{\prime} X$ & $\begin{array}{l}\pi \text { é a variável desempenho medida } \\
\text { pelo retorno sobre o ativo total; CR é o } \\
\text { índice de concentração, MS é a medida } \\
\text { de participação de mercado e EF cor- } \\
\text { responde à medida direta de eficiência } \\
\text { estimada através da metodologia de } \\
\text { fronteira estocástica. }\end{array}$ \\
\hline $\begin{array}{c}\text { Gumbau } \\
\text { e Maudos } \\
(2000)\end{array}$ & $\begin{array}{l}\text { analisar as hipóteses ED e EE } \\
\text { para } 18 \text { setores da indústria } \\
\text { espanhola no período entre } \\
1991 \text { e } 1994 .\end{array}$ & $\pi=\beta_{0}+\beta_{1} C R+\beta_{2} M S+\beta_{3} E F+\alpha^{\prime} X$ & $\begin{array}{l}\text { como proxy para o desempenho foi uti- } \\
\text { lizada a variável margem preço-custo; } \\
\text { as variáveis CR e MS foram utilizadas, } \\
\text { respectivamente, como variáveis de } \\
\text { concentração e participação de merca- } \\
\text { do e a variável EF foi obtida estimando } \\
\text { a função de produção Cobb-Douglas. }\end{array}$ \\
\hline
\end{tabular}

Quadro 1 - Resumo dos principais trabalhos que realizaram análises econométricas utilizando o referencial teórico sobre a relação entre estrutura e desempenho

Fonte: Elaboração própria.

Para o Brasil, foram encontrados trabalhos que estimaram a relação entre estrutura e o desempenho das firmas, mas que analisaram a indústria brasileira incluindo todos os seus setores e, portanto, não foram aplicados a um setor específico. Entre esses trabalhos têm-se os de Mendonça e Lima (2009) e Carvalho Júnior (2006). O trabalho de Mendonça e Lima (2009) analisou a relação entre estrutura e desempenho da indústria brasileira para o período de 2000 a 2006 através de um modelo de painéis dinâmicos. Já Carvalho Júnior (2006) analisou os determinantes do desempenho da indústria brasileira por meio de um grupo de modelos empíricos composto por 4.498 firmas em 106 indústrias e 5.014 firmas para o ano de 2000, utilizando dois enfoques teóricos distintos: o primeiro baseado no paradigma ECD e o segundo baseado nas capacidades internas da firma e nas suas estratégias para competição com enfoque para os 
aspectos teóricos apresentados por Penrose (1959), Chandler (1992) e Nelson e Winter (1982). O Quadro 2 sintetiza os trabalhos desses autores.

\begin{tabular}{|c|c|}
\hline \multicolumn{2}{|c|}{ Mendonça e Lima (2009) } \\
\hline modelo & variáveis utilizadas \\
\hline $\begin{array}{l}\pi_{i t}=\beta_{0}+\beta_{1} \pi_{i t-1}+\beta_{2} H H I_{i t}+\beta_{3} E F_{i t}+\sum_{j=4}^{8} \beta_{j} D_{j}+\varepsilon_{i t} \\
\text { Os autores estimaram três modelos utilizando o método } \\
\text { proposto por Arellano e Bond (1991): 1) incluindo todos } \\
\text { os dados da amostra; 2) incluindo apenas as empresas } \\
\text { intensivas em capital; e 3) incluindo apenas dados das } \\
\text { empresas não intensivas em capital. }\end{array}$ & $\begin{array}{l}\text { variável desempenho }(\pi) \text { foi o valor da transformação industrial } \\
\text { obtida da Pesquisa Industrial Anual do IBGE; variáveis explicativas } \\
\text { foram: índice Herfindahl-Hirchman (HHI) e a variável eficiência (EF) } \\
\text { obtida pela estimação da fronteira estocástica da indústria. }\end{array}$ \\
\hline \multicolumn{2}{|c|}{$\begin{array}{l}\text { Conclusão: Os dois primeiros modelos foram a favor da hipótese híbrida ED e EE, sendo que as variáveis concentração e eficiência } \\
\text { apresentaram coeficientes significativos para explicar a variável desempenho utilizada. Já o último modelo foi a favor da hipótese EE. }\end{array}$} \\
\hline \multicolumn{2}{|c|}{ Carvalho Júnior (2006) } \\
\hline modelo & variáveis utilizadas \\
\hline 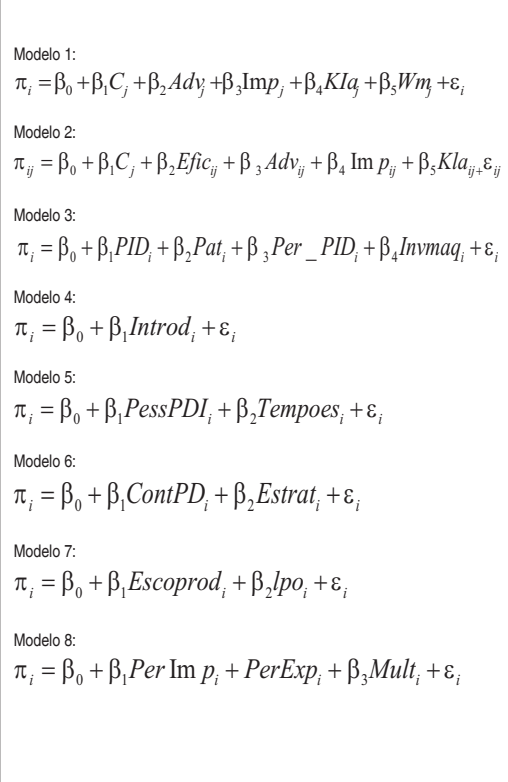 & $\begin{array}{l}\text { Variáveis dependentes }(\pi) \text { testadas nos oito modelos: } 1 \text { ) taxa de } \\
\text { margem de lucro (a taxa de margem de lucro corresponde, segundo } \\
\text { Carvalho Júnior (2006), à receita líquida de vendas total subtraída } \\
\text { dos custos e despesas totais e do gasto com pessoal dividido } \\
\text { pela receita líquida de vendas total); 2) taxa de transformação } \\
\text { industrial, isto é, o valor da transformação industrial em relação ao } \\
\text { valor bruto da produção industrial; 3) participação do mercado; e } \\
\text { 4) produtividade do trabalho. Variáveis exógenas: C (medida de } \\
\text { concentração industrial), Adv (gasto relativo em propaganda), Efic } \\
\text { (medida de eficiência como participação de mercado e produtividade } \\
\text { do trabalho), Imp (percentual de importação da firma em relação } \\
\text { ao gasto com insumos), Kla (intensidade de capital da firma), Wm } \\
\text { (salário médio do trabalhador); PID (se a firma realizou ou não P\&D); } \\
\text { Pat (solicitação ou existência de patentes); Per_PID (percentual gasto } \\
\text { em P\&D); Invmaq (percentual gasto com máquinas e equipamentos); } \\
\text { Introd (introduziu uma nova técnica ou imitação do produto); PessPD } \\
\text { (número de pessoas ocupadas em P\&D); Tempoes (tempo médio } \\
\text { do estudo dos trabalhadores); ContPD (continuidade do programa } \\
\text { de P\&D); Estrat (refere-se ao somatório de seis perguntas do } \\
\text { questionário da PINTEC sobre alguma mudança estratégica } \\
\text { implementada pela firma); Escoprod (soma dos quadrados da } \\
\text { participação dos três produtos produzidos pela firma); lpo (logaritmo } \\
\text { do número de pessoas ocupadas); Per_ Imp (taxa de importação); } \\
\text { Per_Exp (taxa de exportação); Mult (origem do capital: nacional ou } \\
\text { estrangeiro) }\end{array}$ \\
\hline
\end{tabular}

\section{Quadro 2 - Síntese dos trabalhos encontrados na literatura brasileira sobre o ferramental empírico}

Fonte: Elaboração própria.

Nota: *Arellano, M.; Bond, S. Some tests of specification for panel data: Monte Carlo evidence and application to employment equations. Review of Economics Studies, Oxford, v. 58, n. 2, 1991 . 
Em relação à literatura existente, vale ressaltar que o presente artigo, além de analisar um setor específico da indústria brasileira, não pretende testar as hipóteses estrutura-desempenho e eficiência-estrutura apontadas pela literatura, mas sim identificar quais variáveis de estrutura (como índices de concentração industrial CR4 e HHI) e de abertura comercial (como taxa de exportação e taxa de importação) tiveram influência sobre o desempenho das indústrias de celulose e de papel e artefatos de papel no Brasil (essas duas últimas consideradas conjuntamente). É importante destacar que este trabalho é classificado dentro da temática de organização industrial, cujo objetivo é verificar se as variáveis de estrutura de mercado afetam o desempenho das indústrias de celulose e papel no Brasil. Como o período considerado na análise abrange o processo de abertura comercial da economia brasileira, nota-se que as indústrias do setor de celulose e papel nesse período passaram por processos de reestruturação produtiva como forma de ampliar sua capacidade instalada e inserir-se competitivamente no cenário internacional.

Uma vez inserido dentro do contexto econômico global, o setor de celulose e papel no Brasil seguiu, praticamente durante toda a década de 1990, a tendência mundial de concentração produtiva e de reestruturação patrimonial por meio de fusões e aquisições entre grandes empresas, com a finalidade de buscar sinergias para obter reduções de custos, aumento de escala e obter maior poder de competição frente aos grandes players globais. Além disso, esses processos de fusões e aquisições tiveram a finalidade de aumentar o grau de concentração da produção como estratégia para as empresas do setor competirem internacionalmente e diminuir os riscos de prejuízos devido às flutuações de preços, o que, consequentemente, aumenta o desempenho das empresas do setor. Neste artigo foram usados como indicadores alternativos de desempenho a margem preço custo e o lucro bruto das indústrias do setor de celulose e papel.

É importante ressaltar que o foco deste artigo não é o mesmo da literatura que analisa os impactos do comércio internacional sobre o crescimento do produto. Segundo Fraga (2011), há autores como Balassa (1978) que tratam da influência do comércio internacional sobre o crescimento do produto. Balassa (1978) investigou empiricamente a relação entre exportações e crescimento econômico para um grupo de países em desenvolvimento no período de 1960 a 1973. $\mathrm{O}$ autor concluiu que o aumento de $1 \%$ na taxa de crescimento das 
exportações proporciona um aumento de $0,04 \%$ na taxa de crescimento do produto nacional bruto. Além disso, o autor afirma que a orientação comercial dos países considerados em seu estudo tem sido importante para explicar a diferença de crescimento da renda dos países, sendo que as economias com políticas consistentes para estimular exportação conseguiram maior crescimento da renda. Fukuda e Toya (1993) apud Cândido e Lima (2010) afirmam que a argumentação que baliza a afirmativa de que o comércio internacional é um fato de grande influência sobre crescimento econômico está ligada à capacidade do comércio internacional de aumentar a utilização da capacidade produtiva, o que induz ao aumento dos níveis de investimento; melhora a alocação de recursos de acordo com as vantagens comparativas de cada país; aproveita os ganhos de escala, já que amplia o mercado para os produtos do país que amplia sua inserção no comércio internacional; produz melhorias tecnológicas, pois a competitividade passa a ser atributo básico para concorrer no comércio exterior, além das melhorias da capacidade de gerenciamento para responder às pressões competitivas externas. Geralmente, segundo Fraga (2011), a abertura comercial é representada como sendo a razão entre a soma das exportações $(\mathrm{X})$ mais as importações $(\mathrm{M})$, divididas pelo PIB dos respectivos países.

O presente trabalho, diferentemente da literatura que relaciona a evolução do crescimento do comércio internacional sobre o crescimento do produto, trata da relação entre a estrutura (medida pelos índices de concentração e estrutura de capital das indústrias do setor) sobre o desempenho medido pelas variáveis margem preço-custo e lucro bruto das indústrias do setor de celulose e papel o Brasil. As variáveis taxas de exportação e taxa de importação também serão incluídas no modelo para explicar o efeito dos fluxos comerciais dessas indústrias sobre o desempenho destas. 


\section{Metodologia e Dados Utilizados}

Considerando a Equação (1), as alternativas de modelos de Carvalho Júnior (2006), os objetivos a serem alcançados no artigo e a disponibilidade de dados, propõe-se a seguinte equação para mensurar a relação entre desempenho e estrutura no setor de celulose e papel no Brasil:

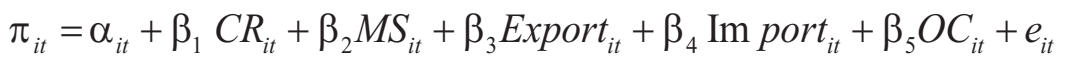

Em que:

$\pi_{i t}$ corresponde à medida de desempenho da indústria $i$ no tempo $t$. As medidas de desempenho a serem testadas são a margem preço-custo (receita líquida de vendas total subtraída dos custos e despesas totais e do gasto com pessoal sobre a receita líquida de vendas total) como proxy para o Índice de Lerner e o lucro bruto das indústrias consideradas na análise (faturamento total das indústrias multiplicado pela margem bruta). Para o cálculo da margem preço-custo são utilizados os dados da Pesquisa Industrial Anual (PIA), e para o cálculo do lucro bruto são utilizados os dados do faturamento do Relatório Estatístico da BRACELPA e os dados da margem bruta da Pesquisa Industrial Anual (PIA).

$C R_{i t}$ é a medida de concentração da indústria $i$ no tempo $t$. São utilizadas a razão de concentração das quatro maiores empresas (CR4) e alternativamente o índice de Herfindahl-Hirschman (HHI), ${ }^{4}$ que mede tanto a participação como a desigualdade entre as empresas que compõem as indústrias de celulose e papel e artefatos de papel. A fonte de dados utilizada são os Relatórios da BRACELPA.

$M S_{i t}$ é a medida de participação de mercado, utilizada como medida de eficiência calculada como percentual da receita líquida de vendas total de cada indústria $i$ em relação ao total da receita líquida de vendas do setor de celulose e papel. A fonte de dados utilizada é a Pesquisa Industrial Anual - PIA IBGE.

Export corresponde à taxa de exportação da indústria $i$ no tempo $t$, e refere-se ao valor das exportações da indústria $i$ sobre a receita líquida de vendas da indústria $i$. A fonte de dados utilizada é o

4 Os cálculos do CR4 e do HHI foram feitos a partir da produção anual como variável indicativa para o período de 1980 a 2010. É importante destacar que o presente trabalho levou em consideração no cálculo dos índices de concentrações os processos de fusões e aquisições que ocorreram entre as empresas ao longo do período considerado na análise. 
Sistema Aliceweb do Ministério do Desenvolvimento, Indústria e Comércio Exterior - MDIC.

Import corresponde à taxa de importação da indústria $i$ no tempo $t \mathrm{e}$ refere-se ao valor das importações da indústria $i$ sobre a Receita Líquida de Vendas da indústria $i$. A fonte de dados utilizada é o MDIC.

$O C$ corresponde à origem do capital da indústria $i$ no tempo $t$. Utilizando as informações da BRACELPA é possível calcular a importância das empresas com capital estrangeiro sobre a produção da indústria total. Logo, calculou-se o total da produção das empresas de capital estrangeiro sobre a produção total da indústria $i$ como forma de verificar se a origem do capital tem influência sobre o desempenho das indústrias em análise.

Dos trabalhos já revisados nos Quadros 1 e 2, espera-se que $\beta_{1}$ e $\beta_{2}$ sejam positivos. Por meio de variáveis de inserção externa (Export, Import e $O C$ ), será analisado o impacto do comércio internacional sobre o desempenho das indústrias. A variável de exportação pode ser considerada uma variável estratégica, pois é uma decisão tomada a partir das competências centrais e estruturais da indústria. Esperase que $\beta_{3}$ seja maior que zero. Já a variável importação busca analisar a vulnerabilidade das indústrias nacionais frente à concorrência internacional. Espera-se que $\beta_{4}$ seja menor que zero. A variável origem do capital está relacionada à participação das empresas estrangeiras dentro de cada indústria em análise. Como as empresas estrangeiras são capazes de competir fora de seu país, espera-se que as mesmas sejam mais eficientes que as empresas domésticas e, portanto, teriam melhor desempenho que os competidores locais. Espera-se que $\beta_{5}$ seja maior que zero.

O subscrito $i$ representa, respectivamente, as indústrias de celulose e de papel e artefatos de papel (essas duas últimas consideradas em conjunto) no Brasil e o subscrito $t$ representa o ano de observação das informações. Tem-se, portanto, que $i=1$ corresponde à indústria de celulose e $i=2$ corresponde à soma das indústrias de papel e artefatos de papel; e $t=1986, \ldots, 2007$ (dados anuais). $\alpha$ e $\beta$ são o conjunto de coeficientes a serem estimados. Com os dados disponíveis e os propósitos do trabalho, a abordagem empírica pertinente é utilizar modelos de painel de dados compreendendo o período de 1986 a 2007. Os dados de painel combinam dados de séries tem- 
porais e dados de corte transversal (cross sections). Os modelos de dados em painel apresentam muitas vantagens como o controle da heterogeneidade individual, menor colinearidade entre as variáveis, e maior número de graus de liberdade, aumentando a eficiência da estimação dos modelos.

Segundo Greene (2003), há os seguintes modelos de dados de painel: modelo pooled (que utiliza a técnica de mínimos quadrados ordinários (MQO) empilhados, sendo que neste caso todos os coeficientes são constantes para todos os indivíduos); modelo de efeito fixo ou de variáveis binárias (nesse caso, a estimação é feita assumindo que a heterogeneidade dos indivíduos se capta na parte constante, que é diferente de indivíduo para indivíduo); e modelo de efeito aleatório ou componente de erro (a estimação é feita introduzindo a heterogeneidade dos indivíduos no termo de erro).

Segundo Greene (2003), a apresentação dos modelos em painel é dada de acordo com a seguinte equação:

$$
y_{i t}=x_{i t}^{\prime} \beta+z_{i}^{\prime} \alpha+e_{i t}
$$

De acordo com Greene (2003), há k regressores em x, não incluindo a constante. A heterogeneidade ou efeito individual é $z_{i}^{\prime} \alpha$ onde $z_{i}$ contém um termo constante e um conjunto de variáveis-grupo específicas ou individuais, que podem ser observadas como habilidades, preferências, características familiares específicas, etc., todas consideradas constantes no tempo. Este é um modelo de regressão clássica. Se $z_{i}$ é observado para todos os indivíduos, pode-se aplicar o método MQO na estimativa.

No Modelo "Pooled", a estimação é feita assumindo que os parâmetros $\beta$ e $\alpha$ são comuns para todos os indivíduos. Tem-se:

$$
y_{i t}=x_{i t}^{\prime} \beta+\alpha+e_{i t}
$$

Este modelo mais simples, que utiliza Mínimos Quadrados Ordinários - MQO "empilhado" para a estimação, assume que o comportamento é uniforme para todos os indivíduos ao longo do tempo e que todas as observações são homogêneas (isto é, da mesma 
população). Assim, neste caso, tanto o intercepto como as inclinações são iguais para todos os indivíduos considerados na análise. É importante destacar que dados em pooling podem apresentar problemas de heterocedasticidade, autocorrelação e correlação contemporânea, isto é, correlação dos termos de erros entre as unidades cross sections.

No Modelo de efeitos fixos, a estimação é feita assumindo que a heterogeneidade dos indivíduos se capta no intercepto, que é diferente de indivíduo para indivíduo. Tem-se a seguinte equação:

$$
y_{i t}=\alpha_{i}+x_{i t}^{\prime} \beta+\varepsilon_{i t}
$$

onde: $\alpha_{i}=z_{i}^{\prime} \alpha$

Segundo Greene (2003), a formulação deste tipo de modelo consiste em assumir que as diferenças entre as unidades cross section podem ser capturadas nas diferenças no parâmetro $\alpha$. Cada $\alpha_{i}$ é um parâmetro desconhecido a ser estimado e é diferente para cada indivíduo, captando diferenças invariantes no tempo. Já o coeficiente $\beta$ é constante para todos os indivíduos e em todo o período de tempo analisado. Assim, no modelo de efeitos fixos controlam-se os efeitos das variáveis omitidas, as quais variam entre os indivíduos da análise, mas que são constantes ao longo do tempo. Em outras palavras, a análise longitudinal se destaca das demais pela sua capacidade de controlar a heterogeneidade existente entre os indivíduos através da estimação dos efeitos individuais isolando, desta forma, os efeitos das variáveis explanatórias não mensuradas pelo econometrista. Para testar se os $\alpha_{i}$ diferem ou não entre as unidades cross section, utiliza-se o teste F. A hipótese nula considera que os termos constantes não diferem entre os diferentes grupos. Sob a hipótese nula $\left(\mathrm{H}_{0}\right)$, o estimador eficiente pode ser obtido por mínimos quadrados pooled. Rejeitando $\mathrm{H}_{0}$, conclui-se que os interceptos são diferentes entre os indivíduos, podendo ser utilizado, portanto, o modelo de efeitos fixos.

Destaca-se que o modelo de efeitos fixos é adequado a situações em que o intercepto de cada indústria pode estar correlacionado com uma ou mais variáveis explicativas em qualquer período de tempo. Entretanto, esse modelo apresenta algumas limitações. De acordo com Wooldridge (2002), a necessidade de se incluir um número muito grande de variáveis dummies pode levar à perda de uma gran- 
de quantidade de graus de liberdade na estimação do modelo. Logo, os estimadores $\hat{\alpha}_{i}$ são melhores quando o número de períodos de tempo observado for grande.

Nos Modelos com efeitos aleatórios, a estimação é feita introduzindo a heterogeneidade dos indivíduos no termo de erro $u_{i}$. Tem-se a seguinte equação:

$$
y_{i t}=\alpha_{i}+\beta^{\prime} X_{i t}+\varepsilon_{i t}
$$

onde $\alpha_{i}=\alpha+u_{i}$

Então,

$$
y_{i t}=\alpha+\beta^{\prime} X_{i t}+u_{i}+\varepsilon_{i t}
$$

É importante destacar que a diferença entre o modelo de efeitos fixos e aleatórios refere-se ao tratamento do intercepto. Os modelos de efeitos fixos pretendem controlar os efeitos das variáveis omitidas que variam entre indivíduos e permanecem constantes ao longo do tempo. Para isto, supõe-se que o intercepto varia de um indivíduo para o outro, mas é constante ao longo do tempo, ao passo que os parâmetros respostas são constantes para todos os indivíduos e em todos os períodos de tempo. No caso do modelo de efeitos aleatórios, entretanto, os interceptos são tratados como variáveis aleatórias. Além disso, no caso do modelo de efeitos fixos (Mínimos Quadrados com Variável Dummy), a diferença entre os indivíduos é captada na parte constante, enquanto para o modelo com efeitos aleatórios (estimado por Mínimos Quadrados Generalizados) estas diferenças são captadas no termo de erro. Estas são as principais diferenças entre os dois modelos em painel.

De acordo com Wooldridge (2002), o ponto crucial na decisão entre o modelo de efeitos fixos e o modelo de efeitos aleatórios reside na questão se $\alpha_{i}$ e $x_{i}$ são correlacionados ou não. Se $\alpha_{i}$ não for correlacionado com $x_{i}$ (variáveis explicativas), o modelo de efeitos aleatórios é o mais apropriado. Através do teste de Hausman (1978), baseado nas diferenças das estimativas de efeitos fixos e aleatórios, é possível verificar se há correlação entre $\alpha_{i}$ e as variáveis explicativas. 
O presente artigo preocupou-se em destacar as diferenças entre as indústrias de celulose e as indústrias de papéis e de artefatos de papéis (estas duas últimas tomadas em conjunto). Portanto, para determinar quais modelos de dados em painel usar (modelo "pooled", modelo de efeitos fixos ou modelo de efeitos aleatórios), buscou-se controlar a heterogeneidade existente entre as indústrias do setor de celulose e papel. Logo, o modelo de efeitos fixos ou o modelo de efeitos aleatórios são os mais apropriados para analisar no trabalho em questão. Para auxiliar na escolha de qual dos dois modelos utilizar, adotou-se o procedimento do teste de Hausman, cuja hipótese nula é a de que as diferenças nos coeficientes não são sistemáticas, sendo que a não rejeição da hipótese nula indica, portanto, que a melhor escolha é o modelo de efeitos aleatórios.

\section{Resultados}

\subsection{Análise das Regressões sobre os Determinantes do Desempenho da Indústria de Celulose e das Indústrias de Papel e de Artefatos de Papel no Brasil}

As estimativas da Equação (2) para a indústria de celulose e para as indústrias de papéis e artefatos de papéis (essas duas tomadas em conjunto) são mostradas nas Tabelas 1 e 2. Na Tabela 1 é considerada como variável de desempenho a margem preço-custo e na Tabela 2 , o lucro bruto das indústrias de celulose, de papéis e de artefatos de papel. Também é importante destacar que foi incluída no modelo uma variável dummy - d2 -para os anos de 1992, 1993 e 1994, pois se observam bruscas alterações na variável dependente nesses anos em relação ao resto do período, o que pode ter surgido no processo de coleta de dados da PIA, pois são anos de altas taxas de inflação na economia brasileira. Além disso, esses anos são também anos de acirramento da concorrência internacional, por conta da abertura comercial de anos anteriores. Segundo Averbug (2002), entre 1988 e 1993, realizou-se amplo processo de liberalização comercial no qual se concedeu maior transparência à estrutura de proteção, eliminaram-se as principais barreiras não tarifárias e reduziram-se gradativamente o nível e o grau de proteção da indústria local. Em 1990, foi instituída a Nova Política Industrial e de Comércio Exterior, que extinguiu a maior parte das barreiras não tarifárias herdadas do período de substituição de importações e definiu-se um cronograma 
de redução das tarifas de importação. As reduções se dariam gradualmente entre 1990 e 1994, de modo que, no final do período, a tarifa máxima seria de $40 \%$, a média de $14 \%$, a modal de $20 \%$ e o desvio-padrão inferior a $8 \%$. Ao se utilizar a variável dependente como sendo a margem preço custo, Tabela 1, constatou-se a ocorrência de multicolinearidade entre a variável MS (market share) e as demais variáveis independentes propostas no modelo pelo fator de inflação da variância - VIF. Por isso, a variável MS foi excluída de algumas regressões. Além da variável de estrutura CR4, também foram realizadas as regressões considerando a variável de estrutura de mercado como sendo o HHI. Nos dois casos, a estatística do teste de Hausman ${ }^{5}$ para os modelos estimados foi não significativa, apontando que o método de estimação de efeitos aleatórios é o que melhor se ajusta aos dados desta pesquisa. Os resultados obtidos na estimação de efeitos fixos e aleatórios não detectaram a presença de autocorrelação serial dos resíduos pelo teste de Wooldridge (2002), não violando a hipótese de não correlação serial, e não detectaram a presença de heterocedasticidade.

Para o caso em que foi considerada a variável de estrutura como sendo o CR4, os resultados não foram satisfatórios. Notou-se que todos os coeficientes estimados das variáveis CR4, Export, Import e OC apresentaram os sinais esperados pelo modelo teórico proposto, entretanto os coeficientes estimados para o CR4 não foram estatisticamente significativos, o mesmo ocorrendo em alguns casos para as variáveis Export e Import.

Considerando a variável de estrutura de mercado como sendo o HHI (Tabela 1), os resultados foram estatisticamente melhores do que os resultados apresentados com a variável CR4, e a estimativa 4 foi a que apresentou o melhor ajuste econométrico. Ela é:

$$
\begin{aligned}
& \pi_{i t}=-1,34+0,37 H_{i t}+0,024 \text { Export }_{i t}-0,09 \operatorname{Im~port~}_{i t}+0,41 O C_{i t}-0,52 d 2+e_{i t} \\
& \begin{array}{lllll}
(-1,17)^{\mathrm{d}} & (1,43)^{\mathrm{c}} & (0,24)^{\mathrm{ns}} & (-1,30)^{\mathrm{d}} & (1,20)^{\mathrm{d}} \quad(-4,64)^{\mathrm{a}} \\
& \mathrm{R}^{2}=0,5938 & \mathrm{~N}=44 &
\end{array}
\end{aligned}
$$

5 A hipótese nula do teste de Hausman é a de que a diferença entre os coeficientes estimados utilizando o método de efeitos fixos e aleatórios não é sistemática. Assim, sob a hipótese nula, o método mais adequado a ser empregado é o de efeitos aleatórios. No caso dos modelos estimados, não foi possível rejeitar a hipótese nula de que a diferença entre os coeficientes não é sistemática e, portanto, indicam que o melhor modelo é o de efeitos aleatórios, visto que o mesmo obedece à condição de ortogonalidade. 
onde: os valores entre parênteses sob os coeficientes estimados referem-se à estatística $\mathrm{t}$ de student: a indica o coeficiente ser estaticamente significativo a $1 \%$, b indica o coeficiente ser estaticamente significativo a $5 \%$, c significativo a $10 \%$, d significativo a $20 \%$ e ns não significativo.

A equação acima mostra que o aumento do índice de concentração HHI tem impacto positivo sobre a margem preço-custo e que um aumento de $1 \%$ nesta variável causa aumento de $0,37 \%$ na medida de desempenho considerada. Já um aumento de $1 \%$ na taxa de importação (Import) diminui a margem preço custo em 0,09\%. A variável origem do capital (OC) apresentou relação positiva com a margem preço custo e, portanto, uma elevação de $1 \%$ nesta variável aumenta a medida de desempenho em $0,41 \%$. Apesar das variáveis taxa de importação e origem de capital serem estatisticamente significativas somente a $20 \%$, os sinais de seus coeficientes apresentaram os sinais esperados.

Ao considerar a medida de lucro bruto como sendo a medida de desempenho das indústrias de celulose, papéis e artefatos de papéis no Brasil, constata-se que o modelo de estimação de efeitos aleatórios é o mais indicado pelo teste de Hausman (Tabela 2). No entanto, em nenhum dos casos, os resultados encontrados foram tão bons como quando se utilizou a MPC como variável dependente. 


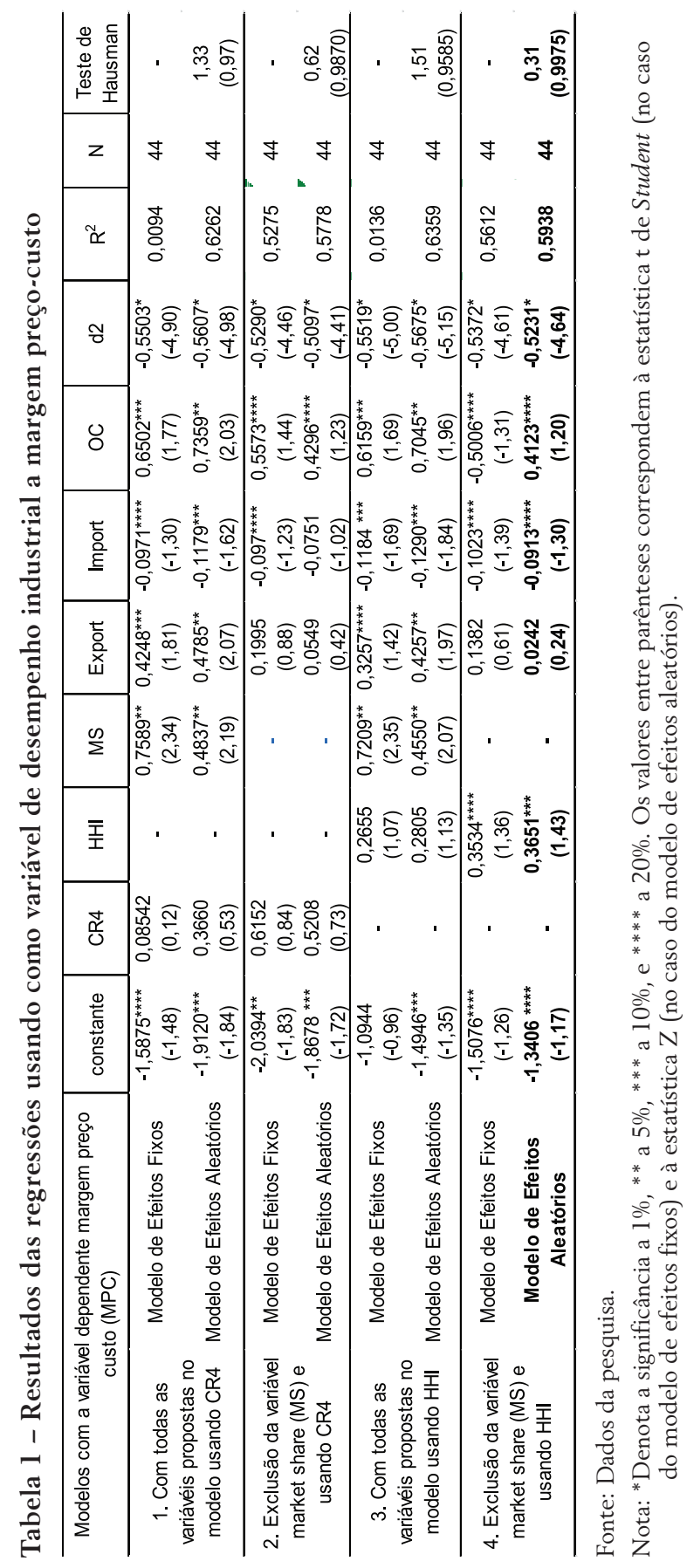




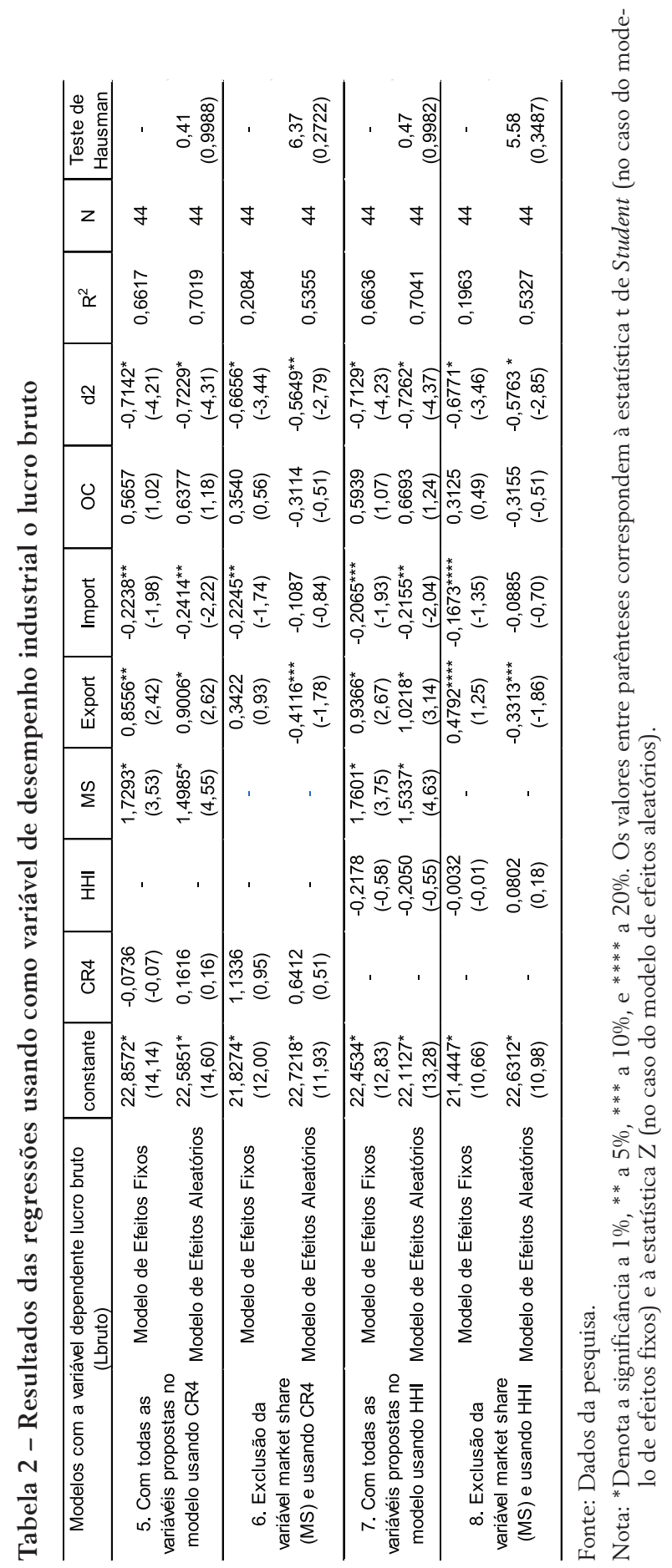

Est. Econ., São Paulo, vol.43, n.1, p.109-137, jan.-mar. 2013 


\section{Considerações Finais}

Este artigo teve como objetivo analisar o impacto da reestruturação e da abertura comercial da indústria de celulose e das indústrias de papel e artefatos de papel (estas duas últimas analisadas conjuntamente) sobre o desempenho dessas indústrias. Para tanto, equações regredindo variáveis de desempenho contra variáveis de estrutura e que mensuram a abertura comercial (como os índices de concentração CR4 e HHI e a variável origem do capital), bem como variáveis relacionadas ao fluxo comercial (taxa de exportação e taxa de importação), utilizando dados organizados em painel, foram estimadas e captando as diferenças entre as indústrias analisadas para o período entre 1986 a 2007.

Os resultados mostraram que o método de estimação de efeitos aleatórios é o que melhor se ajusta aos dados desta pesquisa. Considerando a variável dependente como sendo a margem preçocusto, um aumento no índice de concentração HHI de $1 \%$ aumenta a margem preço-custo em $0,37 \%$. No caso das variáveis de abertura comercial, a variável taxa de exportação e taxa de importação apresentaram os sinais esperados; entretanto, somente a variável taxa de importação apresentou significância estatística (a 20\%). Uma elevação de $1 \%$ na taxa de importação diminui a margem preço-custo em 0,09\%. Já o aumento de $1 \%$ da variável origem do capital acarreta aumento de $0,41 \%$ na medida de desempenho considerada. Este último sugere que o aumento da participação do capital estrangeiro na indústria (aumento de $\mathrm{OC}$ ) aumenta a lucratividade da indústria pelo fato de haver maior integração e cooperação entre as empresas.

No entanto, o sinal negativo e estatisticamente significativo da variável Import sugere que as indústrias do setor de celulose e papel estão mais vulneráveis à rivalidade de competidores potenciais, principalmente no caso de alguns segmentos que compõem as indústrias de papel e de artefatos de papel, em que aumentos na taxa de importação inibem o aumento da lucratividade desses segmentos.

Mesmo com as limitações deste estudo, em especial pela série de tempo usada e a agregação dos dados em nível de indústria e não de firmas, os resultados sugerem que a pesquisa econômica pode contribuir para uma compreensão dos determinantes do desempenho das indústrias do setor de celulose e papel no Brasil. 
Os resultados sugerem que a estrutura de mercado medida pelo índice de concentração HHI realmente afeta o desempenho dessas indústrias medido pela margem preço-custo. Essa variável capta o processo de reestruturação produtiva sofrida pelas indústrias do setor ao longo do período considerado, em que o maior grau de abertura comercial fez com que as empresas do setor passassem por processos de fusões e aquisições, aumentando a concentração dessas indústrias, a fim de se manterem competitivas no mercado internacional e obterem melhores desempenhos frente aos seus concorrentes. No caso dos indicadores que captam o fluxo comercial medido pela taxa de exportação e importação, notou-se que somente a taxa de importação teve influência sobre a margem preço-custo. O seu sinal negativo sugere que o aumento da concorrência internacional, via importações, afeta o desempenho das indústrias de celulose e papel ao longo do período considerado na análise.

\section{Referências}

ASSOCIAÇÃO BRASILEIRA DE CELULOSE E PAPEL - BRACELPA. Relatório estatístico da BRACELPA. São Paulo, 1982-2006.

AAVERBUG, A. Abertura e integração comercial brasileira na década de 90. Disponível em: http://www. bndespar.com.br/SiteBNDES/export/sites/default/bndes_pt/Galerias/Arquivos/conhecimento/ livro/eco90_02.pdf. Acesso em: 28 jun. 2012.

BAER, W. A economia brasileira. 3. ed. São Paulo: Nobel, 2009. 541 p.

BALASSA, B. Exports and economic growth. Journal of Development Economics, New York, v. 5, n.2, p. 181-189, July, 1978.

BERGER, A.N. The profit-relationship in banking: tests of market-power and efficient-structure hypotheses. Journal of Money, Credit and Banking, Ohio, v. 27, n. 2, 1995. Disponível em: <http:// www.jstor.org/stable/2077876>. Acesso em: 29 maio 2009.

BRASIL. Ministério do Desenvolvimento, Indústria e Comércio Exterior. Secretaria de Comércio Exterior. ALICE-WEB: Sistema de Análise das Informações de Comércio Exterior via Internet. 2009b. Disponível em: <http://aliceweb.desenvolvimento.gov.br>. Acesso em: 28 jun. 2009.

CÂNDIDO, M. S.; LIMA, F.G. Crescimento econômico e comércio exterior: teoria e evidências para algumas economias asiáticas. Economia Contemporânea, Rio de Janeiro, v. 14, n. 2, p. 303-325, maio/ago. 2010.

CARRAZZA, L.C.; BACHA, C.J.C. Evolução, estrutura e desafios da indústria de papéis no Brasil: período de 1965 a 2000. In: CONGRESSO DA SOCIEDADE BRASILEIRA DE ECONOMIA E SOCIOLOGIA RURAL, 42., 2004, Cuiabá. Anais... Brasília: SOBER, 2004. p. 1-14.

CARVALHO JÚNIOR, N.S. Lucratividade e desempenho industrial: uma aplicação empírica de duas abordagens teóricas. 2006. Dissertação (Mestrado em Economia) - Faculdade de Ciências Econômicas, Universidade Federal de Minas Gerais, Minas Gerais, 2006. Disponível em: <http://www. cedeplar.ufmg.br/economia/dissertacoes/2006/Nelson_Carvalho.pdf $>$. Acesso em:16 maio 2009. 
CARVALHO JÚNIOR, N.S.; RUIZ, R.M. Determinantes do desempenho das firmas a partir das novas capacitações internas: um estudo de firmas brasileiras. Economia Contemporânea, Rio de Janeiro, v. 12, n. 1, p. 97-127, jan./abr. 2008.

CHANDLER, A.D. Scale and scope: the dynamics of industrial capitalism. 1. ed. London: Harvard University Press, $860 \mathrm{p}$.

DAMANI, P. Vertical integration in the american pulp and paper industry, 1970-2000. 2004. 52 p. Dissertation (Master of Science in the School of Economics) - Institute of Technology, Georgia, 2004. Disponível em: <http://smartech.gatech.edu/bitstream/1853/4989/1/damani_pallavi_200407_MS.pdf>. Acesso em: 11 nov. 2007.

DEMSETZ, H. Industry structure, market rivalry, and public policy. Journal of Law and Economics, Chicago, v. 16, n. 1, 1973. Disponível em: <http://www.jstor.org/pss/724822>. Acesso em: 29 maio 2009.

FEIJÓ, C.A.; CARVALHO, P.G.M.; RODRIGUES, M.S. Concentração industrial e produtividade do trabalho na indústria de transformação nos anos 90: evidências empíricas. Economia, Niterói, v. 4, n. 1, p. 19-52, jan./jun. 2003.

FIUZA, E.P.S. Estudos econométricos em organização industrial no Brasil. In: LISBOA, M.B.; MENEZES-FILHO, N.A. Microeconomia e sociedade no Brasil. Rio de Janeiro: Contra Capa/ FGV/EPGE, 2001. Cap. 12, p. 325-429.

FONSECA, M.G.D. Estudo da competitividade de cadeias integradas no Brasil: cadeia papel e celulose. Campinas, 2003. Disponível em: <http://www.eco.unicamp.br/Neit/cadeias_integradas/ sintese_preliminar.pdf $>$. Acesso em: 11 nov. 2007.

FUKUDA, S; TOYA, H. Conditional Convergence in East Asian Countries: The Role of Exports for Economic Growth. Discussion Paper, Tokyo: Economic Research Institute, Economic Planning Agency, n. 57, 1993.

FRAGA, G. J. Análise da indústria de papel e celulose no Brasil. 2011. 143 p. Tese (Doutorado em Economia Aplicada) - Escola Superior de Agricultura Luiz de Queiroz, Piracicaba, 2011.

GILBERT, R.A. Bank market structure and competion: a survey. Journal of Money, Credit and Banking, Ohio, v. 16, n. 4, 1984. Disponível em: <http://www.jstor.org/stable/1992096>. Acesso em: 19 nov. 2009.

GREENE, W. Econometric analysis. 3. ed. New Jersey: Prentice Hall, 2003. 1026 p.

GUMBAU, M.; MAUDOS, J. Profitability, market structure and efficiency: an application to the Spanish industry. Valencia: Instituto Valenciano de Investigaciones Económicas, 2000. Disponível em: <http://http://www.uv.es/maudosj/publicaciones/ec00-05\%20.pdf>. Acesso em: 17 set. 2009.

HAUSMAN, J.A. Specification tests in econometrics. Econometrica, New York, v. 46, n. 6, p. 1251-1271, Nov. 1978. Disponível em: <http://www.jstor.org/stable/1913827>. Acesso em: 23 nov. 2009.

HAY, D.A. The post 1990 Brazilian trade liberalization and the performance of large manufacturing firms: productivity, market share and profits. Rio de Janeiro: IPEA, out. 1997. (Texto para discussão, 523).

HILGEMBERG, E.M.; BACHA, C.J.C. A indústria brasileira de celulose de mercado e as pressões ambientais. Estudos Econômicos, São Paulo, v. 33, n. 1, p. 1-38, jan./mar. 2003.

INSTITUTO BRASILEIRO DE GEOGRAFIA E ESTATÍSTICA - IBGE. Pesquisa industrial anual. 1996-2007. Disponível em: <http://www.ibge.gov.br/home/estatistica/economia/industria/pia/ produtos/produto2002/default.shtm>. Acesso em: 10 jan. 2010.

LEITE, A.L.S. Concentração e desempenho competitivo no complexo industrial de papel e celulose 1987-1996. 1998. 99 p. Dissertação (Mestrado em Engenharia da Produção) - Universidade Federal de Santa Catarina, Florianópolis, 1998.

LI, H.; MCCARTHY, P.; URMANBETOVA, A. Industry consolidation and price-cost margins: evidence from the pulp and paper industry. Georgia: Center for Paper Business and Industry Studies (CPBIS). Georgia, 2004. Disponível em: $<$ http://www.cpbis.gatech.edu/research/findings/Industry\%20 Consolidation\%20and\%20Price-Cost\%20Margins.pdf>. Acesso em: 20 maio 2009. 
LIMA, G.B.; TARSO FILHO, P.; NEVES, M.F.; CARVALHO, D.T. Integração e coordenação vertical na cadeia de papel e celulose: o caso Votorantim (VCP). Ribeirão Preto, 2006. Disponível em: $<$ http://www.ead.fea.usp.br/Semead/9semead/resultado_semead/trabalhosPDF/143.pd>. Acesso em: 13 nov. 2007.

LOPES, C.R.A. Análise da indústria de papel e celulose no Brasil. 1998. 142 p. Tese (Mestrado em Administração) - Universidade Federal do Rio de Janeiro, Rio de Janeiro, 1998.

MAUDOS, J. Market structure and performance in Spanish banking using a direct measure of efficiency. Applied Financial Economics, London, v. 8, n. 2, 1998. Disponível em: <http://www.uv.es/maudosj/ publicaciones/afe1998.pdf>. Acesso em: 29 maio 2009.

MENDONÇA, E.C.; LIMA, M.A.M. Market structure and performance in Brazilian manufacturing industry using a direct measure of efficiency. In: SEMINÁRIO DIMAC - INSTITUTO DE PESQUISA EM ECONOMIAAPLICADA, 2009, Rio de Janeiro. Anais... Rio de Janeiro: IPEA, 2009. p. 1-41.

MENDONÇA, E.C.; REIS, M.S.; MENDONÇA, R.P.A. Fusões e aquisições, concentração industrial e a eficiência técnica: evidências empíricas para a indústria de transformação brasileira. In: ENCONTRO NACIONAL DE ECONOMIA, 36., 2008, Rio de Janeiro. Anais... Rio de Janeiro: ANPEC, 2008. p. 1-20. Disponível em: <http://www.anpec.org.br/encontro2008/artigos/200807211113060-.pdf>. Acesso em: 13 mar. 2009.

MILLER, R. Market structure and industrial performance: relation of profit rates to concentration. The Journal of Industrial Economics, Chicago, v. 17, n. 2, 1969. Disponível em: <http://www.jstor. org/stable/2097765>. Acesso em: 28 abr. 2009.

MOLYNEUX, P.; FORBES, W. Market structure and performance in European banking. Applied Economics, New York, v. 27, n. 2, p. 155-159, 1995.

NELSON, R.R.; WINTER, S.G. An evolutionary theory of economic change. 1. ed. Cambridge: Harvard University Press, 1982. 437 p.

OHANIAN, N.K. Vertical integration in the U.S. pulp and paper industry, 1900-1940. The Review of Economics and Statistics, Cambridge, v. 76, n. 1, p. 202-207, Feb. 1994. Disponível em: <http:// www.jstor.org/stable/pdfplus/2109840.pdf>. Acesso em: 20 jun. 2007.

PELTZMAN, S. The gains and losses from industrial concentration. Journal of Law and Economics, Chicago, v. 20, n. 2, 1977. Disponível em: http://www.jstor.org/pss/725192>. Acesso em: 29 maio 2009.

PENROSE, E. The growth of the firm. 1. ed. New York: Oxford University Press, 1959. 272 p.

SHEPHERD, W. Tobin's q and structure performance relationship: reply. The American Economic Review, Pittsburg, v. 74, n. 5, p. 1051-1060, 1984. Disponível em: <http:/www.jstor.org/stable/ pdfplus/561.pdf>. Acesso em: 13 jun. 2009.

SILVA, C.L. Competitividade internacional da indústria de papel de imprimir e escrever brasileira sob a ótica da cadeia de valor. 2002. 270 p. Tese (Doutorado em Engenharia de Produção de Sistemas) - Universidade Federal de Santa Catarina, Santa Catarina, 2002.

SMIRLOCK, M. Evidence on the (non)relationship between concentration and profitability in banking. Journal of Money, Credit and Banking, Ohio, v. 17, n. 1, 1985. Disponível em: < http://www.jstor. org/stable/1992507>. Acesso em: 28 maio 2009.

SMIRLOCK, M.; GILLIGAN, T.; MARSHALL, W. Tobin's q and the structure-performance relationship. American Economic Review, Pittsburgh, v. 74, n. 5, 1984. Disponível em: < http://www.jstor. org/stable/1816488>. Acesso em: 28 maio 2009.

TIMME, S.G.; YANG, W.K. On the use of a direct measure of efficiency in testing structure: performance relationships. Georgia: Georgia State University, 1991. p. 31. (Working Paper).

WOOIDRIDGE, J.M.; ROSS, D. Econometric analysis of cross section and panel data. 2. ed. London: The Mit Press Cambridge, 2002. 752 p. 